\title{
Fifty years of violent war deaths from Vietnam to Bosnia: analysis of data from the world health survey programme
}

\author{
Ziad Obermeyer, research scientist, ${ }^{1,2}$ Christopher J L Murray, institute director, ${ }^{1}$ Emmanuela Gakidou, \\ associate professor ${ }^{1}$
}

IInstitute for Health Metrics and Evaluation, University of Washington, Seattle, WA, USA

${ }^{2}$ Harvard Medical School, Boston, MA, USA

Correspondence to: Z Obermeyer ziad_obermeyer@hms.harvard.edu

doi:10.1136/bmj.a137

\section{ABSTRACT}

Objective To provide an accurate estimate of violent war deaths.

Design Analysis of survey data on mortality, adjusted for sampling bias and censoring, from nationally representative surveys designed to measure population health. Estimated deaths compared with estimates in database of passive reports.

Setting 2002-3 World health surveys, in which information was collected from one respondent per household about sibling deaths, including whether such deaths resulted from war injuries.

Main outcome measure Estimated deaths from war injuries in 13 countries over 50 years.

Results From 1955 to 2002, data from the surveys indicated an estimated 5.4 million violent war deaths (95\% confidence interval 3.0 to 8.7 million) in 13 countries, ranging from 7000 in the Democratic Republic of Congo to 3.8 million in Vietnam. From 1995 to 2002 survey data indicate 36000 war deaths annually (16000 to 71000 ) in the 13 countries studied. Data from passive surveillance, however, indicated a figure of only a third of this. On the basis of the relation between world health survey data and passive reports, we estimate 378000 global war deaths annually from 1985-94, the last years for which complete passive surveillance data were available.

Conclusions The use of data on sibling history from peacetime population surveys can retrospectively estimate mortality from war. War causes more deaths than previously estimated, and there is no evidence to support a recent decline in war deaths.

\section{INTRODUCTION}

Estimating mortality due to war is notoriously difficult, but the importance of war as a public health problem as well as a social problem makes it imperative to improve on existing methods of measurement. Accurate estimates of the numbers of deaths are crucial for political, military, and public health planning, as well as for purposes of national history and reconciliation.

The challenges to estimating war mortality are considerable. Civil registration systems that track deaths in peacetime typically fall apart during war, and many wars occur in places without pre-existing surveillance infrastructure. In the absence of reliable data from representative national information systems, three main techniques are currently used to generate estimates.

\section{Existing techniques}

Firstly, a few surveys have been undertaken during wars in specific countries to estimate mortality on the basis of household deaths. ${ }^{1-10}$ These surveys have produced timely estimates, despite the usual problems of estimating adult mortality from surveys ${ }^{11}$ and the additional logistical challenges posed by ongoing warfare. The politicised environment surrounding the Iraq mortality studies in particular, however, has generated considerable debate regarding the statistical validity of such studies. The small number of clusters often necessitated by active combat can lead to high levels of uncertainty. ${ }^{12} 13$ Other researchers draw attention to the difficulties of extrapolating from small sample populations to the national level ${ }^{1415}$ or to the difficulty of constructing a valid counterfactual for estimates of excess mortality. ${ }^{16}$ Some of the most serious criticisms allege systematic bias resulting from sampling methods ${ }^{17}$ or politically motivated overreporting of deaths $s^{12} 161819$-for example of non-household members. ${ }^{20}$ Whatever their merits, these critiques have taken on considerable importance in the public and scientific discourse surrounding estimates of mortality.

Secondly, some studies have attempted to calculate mortality from censuses using demographic techniques that compare the age distribution of a population before and after war. ${ }^{21-24}$ Reliable census data, however, are seldom available at these times and so strong assumptions are required to project existing data forward and backward. In addition, census based methods do not produce accurate estimates for populations with high migration, as occurs during war. ${ }^{25}$

Thirdly, several passive surveillance methods use information from eyewitness and media reports or statistics from mortuaries, gravesites, and health facilities. In the absence of population based data these data are typically the only ones available during ongoing conflicts and represent the most commonly cited sources for government and other estimates of 


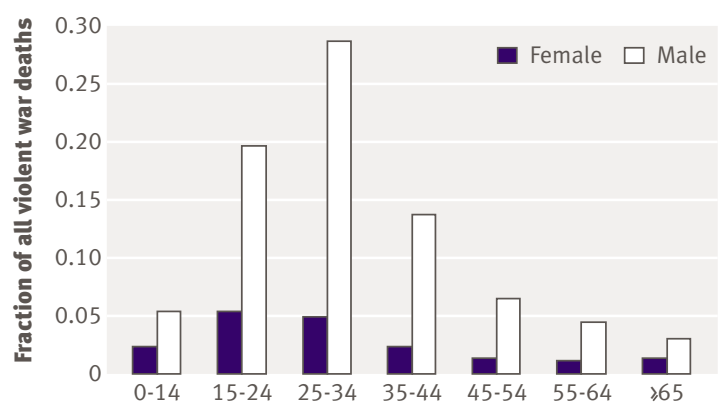

Age group (years)

Fig 1 | Fraction of all violent war deaths by age and sex in 13 survey countries, 1955-2002. As figure considers only war deaths, bars sum to 1

war casualties, as in the current war in Iraq. ${ }^{2627}$ In some post-conflict settings, including war crimes inquiries, active investigations have been undertaken to compile all available evidence from such sources and to supplement them further with intelligence reports, incomplete civil registration records, and missing persons lists. ${ }^{28-30}$

\section{Passive reports}

Passively reported data are subject to several biases. High levels of war related mortality occur in those violent and dangerous areas where eyewitnesses are least likely to go, resulting in systematic underreporting of deaths by media sources. ${ }^{1-2831}$ A similar bias is likely to affect statistics from mortuariesor health facilities, ${ }^{32}$ as well as partial civil registration records from those regions where government infrastructure remains intact. Media and eyewitness reports, and to a lesser degree facility records, are also subject to political pressures, which can result in either exaggeration or under-reporting of deaths. Such reports, however, represent the only source of information on deaths for the vast majority of conflicts, and passive data collection has formed the basis for most efforts to date to analyse global trends in war mortality. A collaboration between Uppsala University and the Peace Research Institute, Oslo, has produced a database (Uppsala/PRIO) that compiles and reconciles passive reports on violent deaths related to war globally from 1900 onward. This database is considered to be more consistent and comparable than other efforts. ${ }^{33}$ The data suggest that violent deaths from war have declined steadily since the second world war and that recent years have been some of the most peaceful of the past century. ${ }^{34}$ This claim lends empirical support to recent research suggesting that overall levels of violent conflict are falling globally ${ }^{35-38}$ and to the view that warfare has become less deadly in recent years thanks to technological innovations and strategic priorities designed to minimise civilian deaths. ${ }^{37} 39$

Given the paucity of population surveys and the known biases in passively reported data, we propose a new approach to estimate violent war deaths, using data on sibling history from household surveys conducted in peacetime and adjusting for known biases. Using nationally representative data from the World Health Organization's 2002-3 world health survey (WHS) programme, we produced estimates of such deaths in 13 countries over the past 50 years. This retrospective method, which is free from the logistical constraints imposed by active combat, is meant to augment and complement information from wartime survey efforts in three ways. Firstly, sample sizes are typically considerably greater and sampling more systematic than during active combat. Secondly, using siblings' histories rather than household deaths addresses some of the serious criticisms of studies in the existing literature-namely, double counting and

Table 1 | World health survey characteristics (number of households, number of siblings), number of deaths captured (for all causes and war, with percentage missing information on year of death), and percentage of deaths missing information regarding cause

\begin{tabular}{|c|c|c|c|c|c|c|c|c|c|}
\hline & \multicolumn{2}{|c|}{ Survey characteristics } & \multicolumn{3}{|c|}{ Sibling deaths, all causes } & \multicolumn{3}{|c|}{ Sibling deaths, war } & \multirow{3}{*}{$\begin{array}{c}\text { Missing cause } \\
\text { of death (\%) }\end{array}$} \\
\hline & \multirow[b]{2}{*}{ Households } & \multirow[b]{2}{*}{ Siblings } & \multirow[b]{2}{*}{ Total } & \multicolumn{2}{|c|}{ Year of death } & \multirow[b]{2}{*}{ Total } & \multicolumn{2}{|c|}{ Year of death } & \\
\hline & & & & Reported & Missing (\%) & & Reported & Missing (\%) & \\
\hline Bangladesh & 5515 & 36627 & 8850 & 7810 & 12 & 21 & 20 & 5 & 14 \\
\hline Bosnia & 1028 & 4095 & 619 & 603 & 3 & 111 & 105 & 5 & 2 \\
\hline Burma & 5848 & 29179 & 3547 & 3531 & 0 & 15 & 15 & 0 & 1 \\
\hline Ethiopia & 4731 & 27819 & 4689 & 3290 & 30 & 80 & 70 & 13 & 20 \\
\hline Georgia & 2394 & 6419 & 1142 & 1098 & 4 & 38 & 38 & 0 & 13 \\
\hline Guatemala & 4473 & 27115 & 4653 & 2883 & 38 & 31 & 21 & 32 & 34 \\
\hline Laos & 4659 & 24503 & 2499 & 2214 & 11 & 59 & 51 & 14 & 5 \\
\hline Namibia & 3768 & 20500 & 2199 & 1362 & 38 & 62 & 33 & 47 & 27 \\
\hline Philippines & 9327 & 60138 & 5630 & 2855 & 49 & 26 & 16 & 38 & 7 \\
\hline Republic of Congo & 1678 & 8548 & 844 & 563 & 33 & 18 & 18 & 0 & 60 \\
\hline Sri Lanka & 6650 & 32369 & 2588 & 1922 & 26 & 99 & 83 & 16 & 27 \\
\hline Vietnam & 4092 & 21583 & 2131 & 2080 & 2 & 290 & 289 & 0 & 14 \\
\hline Zimbabwe & 3965 & 25224 & 4483 & 2707 & 40 & 67 & 44 & 34 & 19 \\
\hline Total & 58128 & 324119 & 43874 & 32918 & $25^{\star}$ & 917 & 803 & $12^{*}$ & $17^{\star}$ \\
\hline
\end{tabular}

* Mean weighted by number of siblings captured in survey. 


\begin{tabular}{|c|c|c|c|c|c|}
\hline & $1955-64$ & $1965-74$ & $1975-84$ & $1985-94$ & $1995-2002$ \\
\hline Bangladesh & - & 27 (13 to 50$)$ & - & - & - \\
\hline Bosnia & - & - & - & 12 (5 to 19$)$ & 7 (2 to 16$)$ \\
\hline Burma & - & - & - & 3 (2 to 5$)$ & - \\
\hline Ethiopia & - & - & 23 (12 to 39$)$ & 22 (12 to 35$)$ & 19 (9 to 36$)$ \\
\hline Georgia & - & - & - & 4 (1 to 8$)$ & - \\
\hline Guatemala & - & - & 2 (1 to 3 ) & - & - \\
\hline Laos & - & 4 (2 to 8$)$ & 2 (1 to 3 ) & & - \\
\hline Namibia & - & - & 1 (0.4 to 2$)$ & $0.3(0.1$ to 1$)$ & 1 (0.2 to 1.3$)$ \\
\hline Philippines & - & - & - & - & 4 (3 to 7$)$ \\
\hline Republic of Congo & - & - & - & - & 1 (0.3 to 3$)$ \\
\hline Sri Lanka & - & - & $10(6$ to 16$)$ & $8(5$ to 13$)$ & 5 (2 to 8$)$ \\
\hline Vietnam & 131 (75 to 211$)$ & $170(102$ to 255$)$ & 81 (44 to 127 ) & - & - \\
\hline Zimbabwe & & $4(2$ to 8$)$ & $10(6$ to 15$)$ & - & - \\
\hline Total & 131 (75 to 211$)$ & 205 (118 to 322) & 129 (70 to 206$)$ & $49(25$ to 81$)$ & 36 (16 to 71$)$ \\
\hline
\end{tabular}

exaggeration of deaths. Finally, we corrected for known problems with mortality surveys-namely, under-representation of families with high mortality and censoring. Such retrospective population based methods can provide accurate data on war deaths, which are crucial for understanding historical trends as well as for future planning.

\section{METHODS}

The world health surveys were carried out in 2002-3 in 70 countries. These nationally representative surveys, which have been described in detail elsewhere ${ }^{40}$ were designed to measure various dimensions of population health and performance of health systems. Surveys in
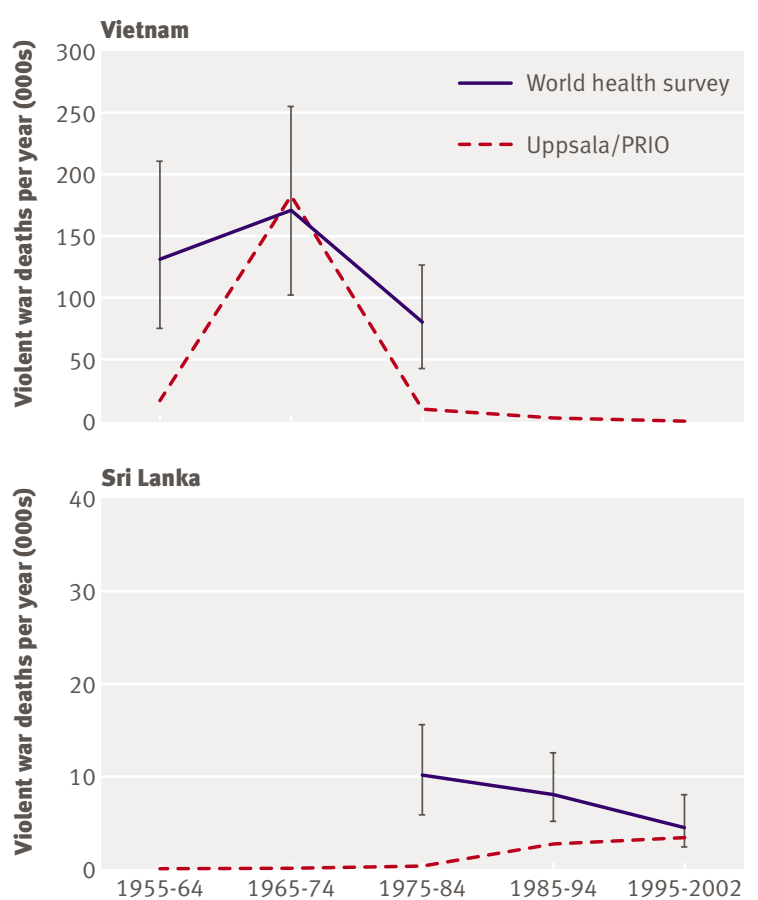

45 countriescollected information on adult deaths, including specific questions about the survival of siblings of the respondent, a randomly selected household member. For siblings who died from injuries, information was collected on the cause of death, including whether the injury was related to war. Of the 45 surveys with data on sibling history, 13 were found to have more than five reported sibling deaths from war injuries in a given 10 year period, and we focused on these countries in the analysis. Table 1 shows selected survey characteristics for the 13 surveys used.

We estimated numbers of violent war deaths by performing a proportional mortality analysis. We
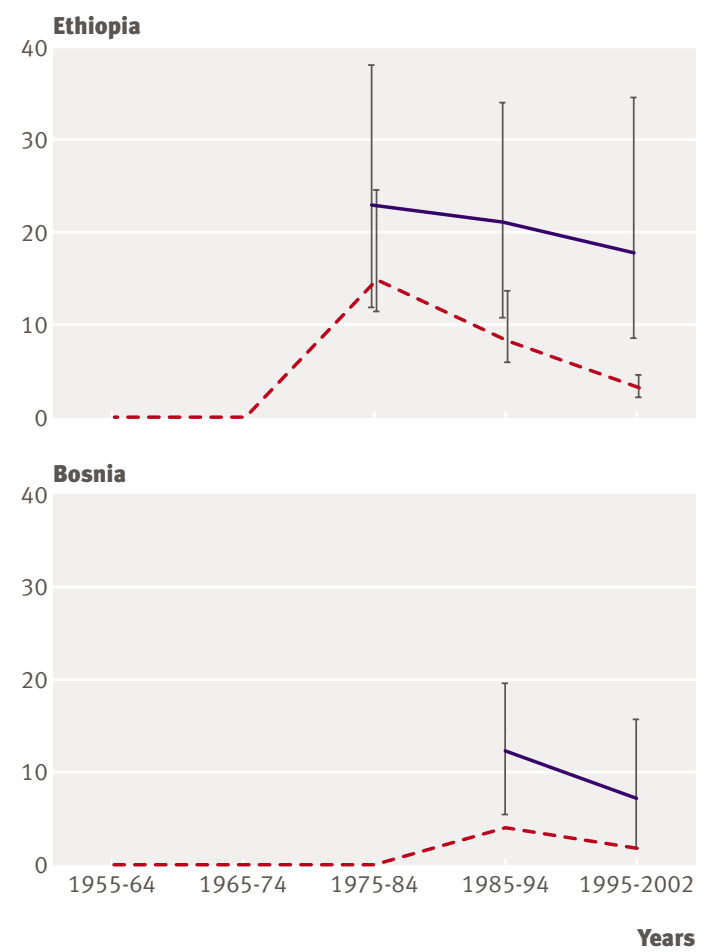
estimated the fraction of total deaths due to war injuries in a given time period based on the survey data and applied this fraction to UN Population Division estimates of total deaths available for all countries from 1955 onward. $^{41}$

We divided the period from 1955 to 2002 into blocks of 10 years; 1955 is the first year for which UN estimates of total deaths are available, and we chose intervals of 10 years to minimise the effect of random error and age heaping in reported ages and years. The last period (1995-2002) is shorter because the survey began in 2002. Across all surveys, information regarding cause of death was missing for $17 \%$ of deaths; we conservatively assumed these to be not related to war. Year of birth for respondents was assigned based on reported age or year of birth. Year of birth for siblings was assigned based either on the reported age difference between the respondent and each sibling or the sibling's reported year of birth. For siblings for whom information on year of birth was missing, we imputed it by randomly drawing a sibling-respondent age difference from a normal distribution with mean and standard deviation based on individual country data from the relevant survey. Overall, year of birth was based on reported age for $83 \%$ of siblings and on reported year of birth for $16 \%$ and was imputed for $1 \%$.

We based year of death on either the respondent's report of how long ago the death occurred or how old the sibling was when he or she died. Information on year of death was missing for $25 \%$ of non-war deaths and $12 \%$ of war deaths. Given the significant difference in these proportions ( $t$ test, $\mathrm{P}<0.001)$, we probabilistically imputed a year of death to avoid upward bias. Overall, we calculated year of death on the reported number of years since the death for $70 \%$ of deaths and on the sibling's reported age at death for $5 \%$ and imputed it for $25 \%$ of deaths.

To calculate probabilities of death for all causes and for war, we divided the number of deaths by the

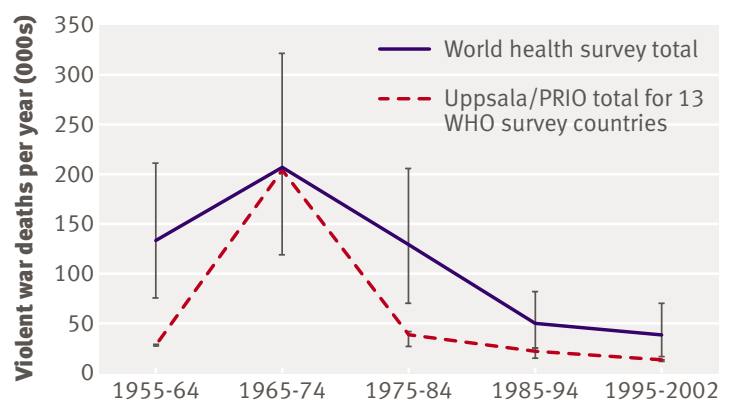

Years

Fig 3 Violent war deaths per year (thousands) in 13 survey countries: world health survey estimates with $95 \%$ confidence intervals and data from Uppsala/PRIO with low-high range (where available)

number of siblings alive in a given 10 year block, after applying two corrections. Firstly, to correct for the fact that families with high rates of mortality are underrepresented in surveys, we weighted siblings by $B_{f} / S_{f}$, where $B_{f}$ is the original sibship size and $S_{f}$ is the number of siblings alive at the time of the survey, according to the method developed by Gakidou and King. ${ }^{42}$ Secondly, we corrected for left and right censoring that occurred in our data because of the limits of respondents' age. Sibling deaths at older ages are less likely to be reported for years longer ago: to consider an extreme example, to report on the death of an 80 year old sibling 80 years ago, a respondent would have to be on average 160 years old. Likewise, adult respondents are less likely to have very young siblings (such as infants) on whom to report deaths in recent time periods. To correct for this censoring, we applied a regression model separately to probability of death in war and not in war. We exponentiated the corrected log probability of death from the war and non-war models and took the ratio of war to all cause probability to calculate the fraction of war deaths by age group,

Table 3 | Total violent war deaths (thousands) from 1955 to 2002, with $95 \%$ confidence intervals for world health survey (WHS) estimates and low-high range for Uppsala/PRIO data (where available), and ratio of WHS estimates to Uppsala/PRIO data

\begin{tabular}{|c|c|c|c|}
\hline & WHS deaths $(95 \% \mathrm{Cl})$ & $\begin{array}{l}\text { Uppsala/PRIO deaths (low-high } \\
\text { range) }\end{array}$ & Ratio of WHS to Uppsala/PRIO \\
\hline Bangladesh & 269 (125 to 505$)$ & 58 & 4.6 \\
\hline Bosnia & 176 (67 to 305$)$ & 55 & 3.2 \\
\hline Burma & 31 (17 to 51$)$ & $37(35-49)$ & 0.8 \\
\hline Ethiopia & 579 (304 to 993 ) & $275(192-459)$ & 2.1 \\
\hline Georgia & 35 (10 to 83$)$ & 3 & 12.0 \\
\hline Guatemala & 20 (10 to 34$)$ & 33 & 0.6 \\
\hline Laos & $62(28$ to 115$)$ & $20(18-20)$ & 3.1 \\
\hline Namibia & $16(6$ to 33$)$ & 61 & 0.3 \\
\hline Philippines & 30 (18 to 48$)$ & $50(49-91)$ & 0.6 \\
\hline Republic of Congo & 7 (2 to 19$)$ & $10(10-13)$ & 0.7 \\
\hline Sri Lanka & 215 (126 to 338) & 61 & 3.6 \\
\hline Vietnam & 3812 (2207 to 5942) & $2096(2095-2096)$ & 1.8 \\
\hline Zimbabwe & 141 (76 to 233$)$ & 28 & 5.1 \\
\hline Total & 5393 (2997 to 8697) & $2784(2695-3026)$ & $3.0^{\star}$ \\
\hline
\end{tabular}


country, and year. We standardised using the WHO standard population ${ }^{43}$ and applied the calculated fraction of war deaths to estimates of total deaths by country and year. We captured uncertainty by simulating 1000 simultaneous draws from the variance-covariance matrix of both war and non-war models to arrive at 1000 estimates of the percentage deaths related to war; the 25th and 976th ranked estimates define the $95 \%$ uncertainty interval. ${ }^{44}$

Finally, we compared our estimates with those from the Uppsala/PRIO database using a linear model, with survey estimated war deaths from 1955-2002 as the dependent variable and Uppsala/PRIO war deaths from the same period as the independent variable. We used the relation derived from this model to adjust the global historical trend observed in the Uppsala/PRIO data. (A technical appendix with more details on the methods is available at http://healthmetricsandevalua tion.org/resources/pubs.html.)

\section{RESULTS}

A total of 43874 sibling deaths were reported in the 13 surveys, of which 917 were a result of war injuries. Some 38613 deaths, of which 797 were due to war, occurred after 1955 and were eligible to be included in our analysis. Figure 1 shows the age and sex distribution of all violent war deaths captured in 13 countries from 1955 to 2002 . Among war deaths, 58\% were in people aged 15 to 34 and $81 \%$ were in males.

Table 2 presents total survey estimates of violent war deaths by 10 year intervals. Our analysis indicates that there were 36000 war deaths annually from 1995 to 2002 in these countries $(95 \%$ confidence interval 16000 to 71000$)$. The time period with the highest war deaths was 1965-74, with 205000 deaths a year, largely attributable to the Vietnam war.

Table 3 shows the total number of deaths by country from 1955-2002 estimated from the surveys, alongside data from Uppsala/PRIO. Survey estimates indicate that a total of 5.4 million ( 3.0 to 8.7 million) violent war deaths occurred from 1955 to 2002 in 13 countries, ranging from 7000 in the Republic of Congo to 3.8 million in Vietnam. The average ratio of survey estimates to Uppsala/PRIO data is 3 , implying that media estimates capture on average a third of the number of deaths estimated from population based surveys. The largest differences were in Bangladesh, Georgia, and Zimbabwe. Apart from Georgia, where the absolute numbers were small, the difference between the two sources was most pronounced in Bangladesh, where the survey shows 269000 deaths compared with 58000 in the Uppsala/PRIO database during the conflict leading to that country's independence, and in Zimbabwe, where the survey estimates nearly 130000 deaths compared with Uppsala/PRIO's 28000 . The two estimates are closest in CongoBrazzaville (7000 in the world health survey and 10000 in Uppsala/PRIO) and Burma (also known as Myanmar) (31 000 and 37 000, respectively). Uppsala/ PRIO provides only limited information on uncertainty, in the form of a low to high range; this is presented where available.

The rank order correlation coefficient between the two sets of estimates is 0.57 , which indicates considerable discrepancy between the two sources on the relative size of the conflicts. Both sources agree that, among these countries, Vietnam and Ethiopia had the greatest number of deaths. Figure 2 presents deaths per year in Vietnam, Ethiopia, Sri Lanka, and Bosnia from the world health survey and Uppsala/PRIO. The survey estimates are consistently higher, except during the period 1965-74 in Vietnam, when the two estimates are not significantly different; this 10 year period was the interval with the most estimated war deaths of all the time periods studied in this analysis. Figure 3 presents survey estimates alongside Uppsala/PRIO data for total yearly deaths across all 13 survey countries combined. Although the levels of deaths are different between the two sources, the time trends in war deaths are similar at the aggregate level.

Figure 4 shows a scatter plot comparing survey estimates with Uppsala/PRIO data for total deaths from 1955-2002 and an equivalence line, with a slope of 1 , indicating the area of the graph at which survey and Uppsala/PRIO estimates are equal. The fact that most estimates lie above the equivalence line shows that survey estimates are generally higher. We applied this relation to all historical data in the Uppsala/PRIO database to arrive at the adjusted Uppsala/PRIO estimates shown in figure 5 . The period 1985-94 is the last full interval for which Uppsala/PRIO data were available disaggregated at country level. As expected, the adjusted number of deaths was greater than the reported number in all time periods, with a threefold difference in the most recent period. The adjusted estimates in figure 5 suggest that there were 378000 global war deaths annually (156000 to 614000) between 1985 and 1994. The adjusted estimate of

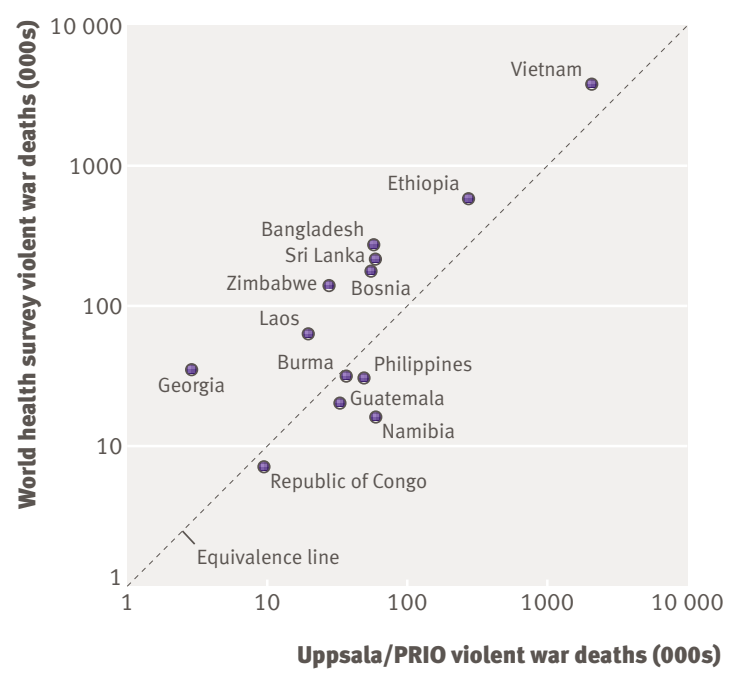

Fig 4 | World health survey estimates against Uppsala/PRIO data for total violent war deaths(thousands) from 1955 to 2002, with equivalence line at which survey and Uppsala/PRIO estimates are equal (log scale) 


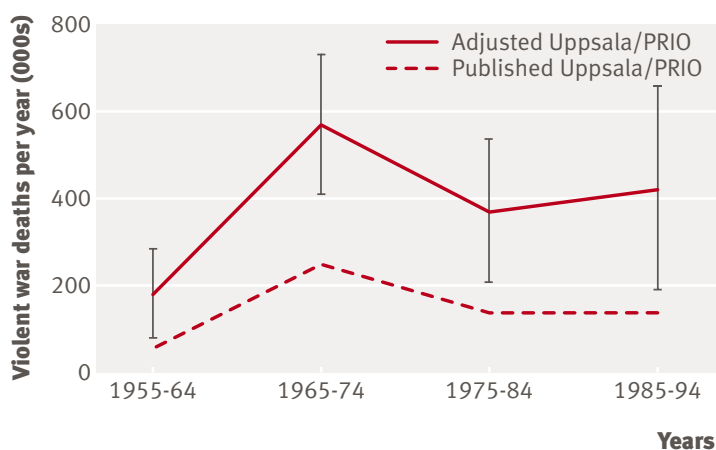

Fig 5 | Uppsala/PRIO violent war deaths per year from 1945 to 1994 and adjusted war deaths per year (thousands) with 95\% confidence intervals, based on relation between Uppsala/PRIO data and world health survey estimates

deaths for this most recent period is 2.2 times higher than our estimate of deaths during the most intense period of the Vietnam war.

\section{DISCUSSION}

Household surveys can be used to retrospectively estimate war deaths over time. The localisation in time of deaths captured by the world health survey is largely consistent with patterns described in qualitative historical accounts. The survey captured a total of 290war deaths in Vietnam, of which 155 were reported between 1965 and 1975, the period widely considered to be the most deadly phase of the war. ${ }^{45}$ Similarly, in Ethiopia the highest level of war deaths is estimated to be between 1975 and 1984, a period beginning with the deposition of Haile Selassie by the Derg and followed by open war in Somalia and Eritrea and the so called "red terror" when many civilians are thought to have been killed. Approximate time localisation of deaths by survey respondents seems to remain intact for long periods: the survey in Paraguay, for example, captured 62 deaths between 1925 and 1934, of which eight were war deaths, coincident with the Chaco war between Paraguay and Bolivia. We could not apply our method to estimate war deaths in this war only because UN estimates of total deaths by country are unavailable before 1955. The fact that respondents in certain household surveys are able to localise the time of the death of their sibling as far back as six decades is remarkable, but it is important to note that the ability to do so is likely to vary by country. Little empirical information about recall bias exists in general because of the lack of an ideal standard by which to judge its degree and determinants (though research on this topic is ongoing ${ }^{46}$ ). The salience of the WHO survey data, however, might indicate that war deaths are less subject to recall bias than other deaths, perhaps because of the young age of victims and strong emotional associations for family members.

Our analysis also suggests that war kills many more people than previously estimated. Data from the Uppsala/PRIO database indicate that an average of 137000 died globally each year between 1985 and
1994, while we estimate a figure of nearly 378000 over the same period. In addition to the absolute number of deaths, comparison of the pattern of deaths over time in survey estimates might lead to different conclusions about trends compared with data from media reports, both at country level and globally. Survey estimates from Sri Lanka suggest a consistent decline in deaths since 1975, while the Uppsala/PRIO estimates show an increase starting in 1985-94. In Ethiopia on the other hand, survey estimates indicate that deaths declined far more slowly than media reports indicate. Our adjustments to the Uppsala/PRIO data likewise do not support the claim that war deaths are declining globally. Overall, nationally representative surveys yield estimates of war deaths that are less optimistic than those based on passive surveillance, implying that it would rarely be appropriate to take such data as a true reflection of the magnitude or trend of deaths.

These findings suggest that the strong claims made on the basis of current data from media reportsnamely, that the number of deaths related to war has declined consistently since the mid-20th century and that recent wars have killed relatively few peopleshould be re-evaluated. Our analysis suggests a method for adjustment of passive surveillance data, which might be the only option when other data are not available. Such approximate methods, however, are no substitute for real data as the adjusted uncertainty intervals are large, even without taking into account uncertainty in the point estimates on which the model is based. More resources are urgently needed for empirical measurement of war deaths.

\section{Limitations}

Our study has several limitations that might influence the interpretation of our results. Firstly, as the survey instrument collects information on deaths from war injuries, our estimates capture only direct violent deaths from war, not all excess deaths attributable to war. Previous studies have shown that while in some countries most war deaths result from such direct injuries, ${ }^{167}$ in other settings, such as those with less developed health infrastructure or worse overall health, violent deaths represent only a small fraction of total excess mortality. ${ }^{2}$ Secondly, there are several potential sources of bias in survey data. Recall bias might have resulted in an underestimate of war deaths as deaths that happened longer ago might be less likely to be reported, particularly in younger age groups. We address this by using corrected probabilities of death from the statistical model, but it is possible that our correction is insufficient.

The inability of surveys to capture families with no survivors is another source of downward bias; while simulation evidence suggests that these families account for only a small proportion of all mortality, ${ }^{42}$ this problem is likely to be more acute in war settings than in other high mortality settings. Overall, we think that the estimates presented here should be viewed as conservative, given these sources of downward bias. 


\section{WHAT IS ALREADY KNOWN ON THIS TOPIC}

The numbers of deaths caused by war have been documented by population based surveys in countries and areas such as Iraq, the Democratic Republic of the Congo, Kosovo, and Darfur

Media reports of war deaths are available in most countries with active wars, and these have also been used to generate estimates for individual countries and globally; but these numbers are generally subject to numerous biases

\section{WHAT THIS STUDY ADDS}

Population based estimates of violent war deaths for 13 countries from 1955-2002, including Vietnam, Bosnia, and Ethiopia, are considerably higher than most previous estimates

In these 13 countries, media reports captured only about a third of all deaths estimated from population based surveys

The new method of adjusting numbers reported in the media yields a more realistic global estimate of the number of violent war deaths per year

Population based surveys conducted in peacetime are a useful and versatile tool for estimating war deaths retrospectively, as well as for tracking adult mortality more generally

Results could also be biased upwards if deaths related to war are reported more frequently or more accurately than other deaths. The survey instrument was designed to minimise this error by asking respondents to enumerate all their siblings (both alive and dead) before answering specific questions about siblings who died. Imputation of missing year of death also corrects for poorer reporting of the timing of non-war deaths.

Thirdly, as the survey was not specifically designed to measure war deaths, the absolute number of sibling deaths captured is small, leading to considerable uncertainty around our point estimates of war deaths - this might be a consistent feature of any survey based estimate of adult mortality, particularly cause specific estimates like our study and previous studies of war mortality. Additional uncertainty might have been introduced into our results by using the UN estimates of total deaths; however, these numbers are the only available source of information on mortality level for these country periods. Fourthly, we restricted our estimates to country periods with more than five sibling war deaths to reduce uncertainty; doing so, however, might have excluded information from small conflicts, which account for less than $1 \%$ of all deaths.

Finally, the absence of an ideal standard measurement of war mortality-which is the reason that alternative techniques such as surveys are neededprevents us from validating our estimates with respect to true numbers. In the absence of credible vital registration data during wartime, the prospect of a validation study against a standard dataset is unlikely. We were unable to locate estimates of deaths from wartime surveys with which to compare our estimates in the 13 countries studied; nor to our knowledge are any future surveys planned in these countries, which could have served to check the consistency of the estimates.

\section{Comparisons with other sources}

One source of comparison in Vietnam is an analysis of that country's life history survey, which yielded an estimate of 966000 war deaths between 1965 and $1975,{ }^{47}$ considerably lower than the world health survey estimate (1.7 million). The authors acknowledge, however, that the Vietnam life history survey results are biased downwards because rural areas with higher mortality were under-represented and estimates were not corrected for under-representation of high mortality families. In addition, the small sample (403 households compared with 4089 in the world health surveys) might have missed clusters of high mortality areas.

Another comparison can be made between survey data and the estimate of 97000 dead and missing in Bosnia in 1991-5 by the Research and Documentation Centre in Sarajevo, ${ }^{48}$ which has compiled a high quality database of records, testimonies, and eyewitness and historical reports. ${ }^{49}$ As with similar efforts in Iraq, ${ }^{27}$ reported data provide a useful minimum estimate of deaths: our estimate of 167000 deaths is higher than the centre's figure but still considerably lower than other estimates, which have ranged up to $329000 .^{30}$ The centre's database also permits comparison of time trends, which indicate that most deaths occurred from 1992 to 1994. The general trend in both sets of numbers is similar, with a decrease in deaths in 1995-2002 relative to $1985-94$, corresponding to the final year of the war.

As a final point of comparison, we applied our correction method, derived from the comparison of survey estimates with Uppsala/PRIO data, to data from the Iraq Body Count project's most recent report of 86539 (the midpoint of the 82772 to 90305 range reported in April 2008) dead in Iraq since 2003. ${ }^{27}$ Our adjusted estimate of 184000 violent deaths related to war falls between the Iraq Family Health Survey estimate of 151000 (104000 to 223000$)^{9}$ and the 601000 estimate from the second Iraq mortality survey by Burnham and colleagues. ${ }^{1}$

\section{Conclusions}

Large scale population based surveys conducted in peacetime, despite their limitations, hold promise for measurement of war mortality for at least three reasons. Firstly, these surveys have several attributes (such as small sampling units, large numbers of clusters, stratification, random selection of households within cluster $^{50}$ ) that are better suited to producing estimates of violent deaths - which tend to be geographically clustered - than those typically available during active humanitarian emergencies. ${ }^{51}$ Future surveys could reduce uncertainty around estimates from sibling histories by several techniques, including larger sample sizes, multiple non-sibling respondents per household, and more structured sibling histories. The survey performed well in the setting of some ongoing conflicts, such as Ethiopia and Sri Lanka, each gathering data on around 30000 siblings with low non-response rates; it is clear, however, that the questionnaire and study design would need to be modified for use during high intensity conflicts. Secondly, household surveys in 
peacetime can be implemented quickly and relatively inexpensively. Finally, as population health surveys are not specifically designed to measure war mortality, and as respondents are asked to provide complete information on all of their siblings before survival status and cause of death are ascertained, there is less scope for exaggeration or double counting of deaths. In addition, such surveys can also provide information on causes of adult mortality other than war: recent advances in verbal autopsy techniques ${ }^{52-56}$ show promise for overcoming the many well known limitations of such cause of death data.

Accurate estimates of war mortality are crucial for planning on several different levels. Political, military, and public health leaders must have credible information on the number of deaths to plan properly before, during, and after wars. The public must also be aware of the human cost of wars. Information on war deaths is useful in the investigation of the scope of war crimes, as in the Nuremburg Trials after the second world war or the international criminal tribunal for the former Yugoslavia. $^{3057}$ Finally, an accurate count of the number of deaths in war is an important part of a nation's history. The South African Truth and Reconciliation Commission is only one example of how a frank accounting of past tragedies is helping to make future ones less likely.

We thank Michael VanRooyen, Les Roberts, Frederick M Burkle, Emmanue D'Harcourt, Eric Werker, the participants at the 2007 Harvard-Dartmouth Humanitarian Conference, and the peer reviewers for their help and insights.

Contributors: ZO, CJLM, and EG designed the study. ZO and EG performed statistical analyses. ZO, CJLM, and EG drafted the manuscript and approved the final version. $Z 0$ is guarantor.

Funding: Bill and Melinda Gates Foundation. WHO funded the world health surveys.

Competing interests: None declared.

Ethical approval: The world health surveys were approved by WHO's

ethical review process.

Provenance and peer review: Not commissioned; externally peer reviewed.

1 Burnham G, Lafta R, Doocy S, Roberts L. Mortality after the 2003 invasion of Iraq: a cross-sectional cluster sample survey. Lancet 2006;368:1421-8.

2 Coghlan B, Brennan R, Ngoy P, Dofara D, Otto B, Clements M, et al. Mortality in the Democratic Republic of Congo: a nationwide survey. Lancet 2006;367:44-51.

3 Depoortere E, Checchi F, Broillet F, Gerstl S, Minetti A, Gayraud O, et al. Violence and mortality in West Darfur, Sudan (2003-04): epidemiological evidence from four surveys. Lancet 2004:364:1315-20.

4 Grein T, Checchi F, Escriba JM, Tamrat A, Karunakara U, Stokes C, et al. Mortality among displaced former UNITA members and their families in Angola: a retrospective cluster survey. BMJ 2003;327:650-3.

5 Hagan J, Palloni A. Death in Darfur. Science 2006:313:1578-9.

6 Roberts L, Lafta R, Garfield R, Khudhairi J, Burnham G. Mortality before and after the 2003 invasion of Iraq: cluster sample survey. Lancet 2004:364:1857-64.

7 Spiegel PB, Salama P. War and mortality in Kosovo, 1998-99: an epidemiological testimony. Lancet 2000;355:2204-9.

8 Uganda Ministry of Health. Health and mortality survey among internally displaced persons in Gulu, Kitgum and Pader districts, northern Uganda. Uganda Ministry of Health, 2005. www.who.int/hac/crises/uga/sitreps/Ugandamortsurvey. pdf.

9 Alkhuzai AH, Ahmad IJ, Hweel MJ, Ismail TW, Hasan HH, Younis AR, et al. Violence-related mortality in Iraq from 2002 to 2006. N Englj Med 2008;358:484-93.

10 Valenciano M, Gergonne B, Morgan O, Aramburu C, Cawthorne A, D'Ancona FP, et al. Retrospective mortality survey among the internally displaced population, Greater Darfur, Sudan, August 2004. Geneva: World Health Organization,

2004. www.who.int/disasters/repo/14656.pdf

11 Gakidou E, Hogan M, Lopez AD. Adult mortality: time for a reappraisal. Int J Epidemiol 2004;33:710-7.

12 Jha P, Gajalakshmi V, Dhingra N, Jacob B. Mortality in Iraq. Lancet 2007;369:101.

13 Kane D. The Lancet surveys of mortality in Iraq. 2007. http://ftp.openbsd.dk/cran/web/packages/lancet. iraqmortality/vignettes/mortality.pdf.

14 Bird S. Military and public-health sciences need to ally. Lancet 2006;364:1831-3.

15 Guha-Sapir D, Degomme 0, Pedersen J. Mortality in Iraq. Lancet 2007;369:102.

16 Zeger S, Johnson E. Estimating excess deaths in Iraq since the USBritish-led invasion. Significance 2007:4:54-9.

17 Johnson N, Spagat M, Gourley S, Onnela JP, Reinert G. Bias in epidemiological studies of conflict mortality. www.rhul.ac.uk/ Economics/Research/conflict-analysis/iraq-mortality/BiasPaper. html.

18 Bohannon J. Epidemiology: Iraqi death estimates called too high; methods faulted. Science 2006;314:396-7.

19 Giles J. Death toll in Iraq: survey team takes on its critics. Nature 2007; $446: 6-7$

20 Apfelroth S. Mortality in Iraq. Lancet 2005;365:1133.

21 Banister J, Johnson EP. After the nightmare: the population of Cambodia. In: Kiernan B, ed. Genocide and democracy in Cambodia: the Khmer Rouge, the United Nations and the International Community, Monograph series 41. New Haven: Southeast Asian Studies, Yale University, 1993:65-139.

22 Heuveline P. "Between one and three million": towards the demographic reconstruction of a decade of Cambodian history (197079). Popul Stud (Camb) 1998;52:49-65.

23 Kiernan B. The demography of genocide in Southeast Asia-the death tolls in Cambodia, 1975-79, and East Timor, 1975-80. Critical Asian Studies 2003;35:585-97.

24 Neupert RF, Prum V. Cambodia: reconstructing the demographic stab of the past and forecasting the demographic scar of the future. Eur $J$ Popul 2005;21:217-46.

25 Hill K. Adult mortality in the developing world: what we know and how we know it. Training workshop on HIV/AIDS and adult mortality in developing countries. New York: United Nations Population Division, 2003.

26 Associated Press. Iraqi health minister estimates as many as 150,000 Iraqis killed by insurgents. International Herald Tribune 9 November 2006. www.iht.com/articles/ap/2006/11/09/europe/ EU_GEN_Austria_Iraqis_Killed.php.

27 Iraq Body Count Project. Iraq Body Count: documented civilian deaths from violence. Iraq Body Count Project, 13 April 2008; www. iraqbodycount.org/.

28 Ball P, Kobrak P, Spirer HF. State violence in Guatemala, 1960-1996: a quantitative reflection. Washington, DC: American Association for the Advancement of Science, 1999.

29 Rummel R. China's bloody century: genocide and mass murder since 1900. New Brunswick: Transaction, 1991.

30 Tabeau E, Bijak J. War-related deaths in the 1992-1995 armed conflicts in Bosnia and Herzegovina: a critique of previous estimates and recent results. Eur J Popul 2005;21:187-215.

31 Iraq Body Count Project. IBC response to the Lancet study estimating "100,000" Iraqi deaths. Iraq Body Count Project, 11 July 2004. www. iraqbodycount.org/analysis/beyond/lancet100000/.

32 Knickmeyer E. One-day toll in Iraq combat is highest for US in months. Washington Post 19 October

2006. www.washingtonpost.com/wp-dyn/content/article/2006/ 10/19/AR2006101900295.html.

33 Lacina B, Gleditsch NP. Monitoring trends in global combat: a new dataset of battle deaths. Eur J Popul 2005;21:145-66.

34 Lacina B, Gleditsch NP, Russett B. The declining risk of death in battle. Int Stud Q 2006;50:673-80.

35 Easterbrook G. The end of war? Explaining fifteen years of diminishing violence. New Republic 2005;May:18-21.

36 Gurr T, Khosla D, Marshall M. Peace and conflict 2001: a global survey of armed conflicts, self-determination movements, and democracy. College Park, MD: University of Maryland Center for International Development and Conflict Management, 2001.

37 Mack A. Human security report 2005: war and peace in the 21st century. New York: Oxford University Press, 2008.

38 Mueller J. Policing the remnants of war. J Peace Res 2003;40:507-18.

39 Boot M. The new American way of war. Foreign Aff 2003;82:41-58.

40 Ustun TB, Chatterii S, Villanueva M, Bendib L, Celik C, Sadana R, et al. WHO multi-country survey study on health and responsiveness 2000 2001. Geneva: World Health Organization, 2001.

41 United Nations Statistics Division. United Nations common database. 25 July 2007. http://unstats.un.org/unsd/cdb/cdb_help/ cdb_quick_start.asp. 
42 Gakidou E, King G. Death by survey: estimating adult mortality without selection bias from sibling survival data. Demography 2006;43:569-85.

43 Ahmad O, Boschi-Pinto C, Lopez A, Murray C, Lozano R, Inoue M. Age standardization of rates: a new WHO standard. Geneva: World Health Organization, 2001.

44 King G, Tomz M, Wittenberg J. Making the most of statistical analyses: improving interpretation and presentation. $\mathrm{Am}$ J Pol Sci 2000;44:347-61.

45 Harrison JP. History's heaviest bombing. In: Werner JS, Huynh LD, eds The Vietnam war: Vietnamese and American perspectives. Armonk, NY: M E Sharpe, 1993:130-9.

46 Murray CJL. Population health metrics research consortium project. Grand challenges in global health, 2008. www.gcgh.org/ MeasureHealthStatus/Challenges/PopulationHealth/Pages/ ConsortiumProject.aspx.

47 Hirschman C, Preston S, Loi VM. Vietnamese casualties during the American war: a new estimate. Popul Dev Rev 1995;21:783-812.

48 Center for Research and Documentation S. Research results. Sarajevo: Center for Research and Documentation, 2007. www.idc.org.ba/presentation/research_results.htm.

49 Ball P, Tabeau E, Verwimp P. The Bosnian book of dead: assessment of the database. Sarajevo: Research and Documentation Center, 2007.

50 Macro International. Sampling manual: DHS-III basic documentation, No 6. Calverton, MD: Macro International, 1996.
51 Checchi F, Roberts L. Interpreting and using mortality data in humanitarian emergencies: a primer for non-epidemiologists. Network Paper No 52. London: Humanitarian Practice Network, 2008. www.redr.org/redr/support/TSS/doc/ mortality_OliverMorgan.pdf.

52 Baiden F, Bawah A, Biai S, Binka F, Boerma T, Byass P, et al. Setting international standards for verbal autopsy. Bull World Health Organ 2007;85:570-1.

53 Lopman BA, Barnabas RV, Boerma JT, Chawira G, Gaitskell K, Harrop T, et al. Creating and validating an algorithm to measure AIDS mortality in the adult population using verbal autopsy. PLoS Med 2006;3:1273-81.

54 Murray CJL, Lopez AD, Barofsky JT, Bryson-Cahn C, Lozano R. Estimating population cause-specific mortality fractions from inhospital mortality: validation of a new method. PLoS Med 2007;4:1754-65.

55 Setel PW, Rao C, Hemed Y, Whiting DR, Yang GH, Chandramohan D, et al. Core verbal autopsy procedures with comparative validation results from two countries. PLoS Med 2006;3:1282-91.

56 Yang GH, Rao C, Ma JM, Wang LJ, Wan X, Dubrovsky G, et al. Validation of verbal autopsy procedures for adult deaths in China. Int J Epidemiol 2006;35:741-8.

57 Brunborg H, Lyngstad TH, Urdal H. Accounting for genocide: How many were killed in Srebrenica? Eur J Popul 2003;19:229-48.

Accepted: 23 April 2008 